\title{
Facial Paralysis in Children with Hypertension
}

\author{
A. V. C. LLOYD, D. E. JEWITT, and J. D. LLOYD STILL \\ From The Hospital for Sick Children, Great Ormond Street, London W.C.1
}

A child was recently seen in whom a lower motor neurone facial palsy was one of the presenting signs of malignant hypertension. The association between facial paralysis and hypertension was first noted by Moxon in 1869 . Although nearly 100 years have elapsed since then, this clinical picture has received little attention. Under the title: 'Apoplexy into Canal of Fallopius' Moxon described a patient with Bright's disease who had a lower motor neurone facial palsy. Dissection of the temporal bone at necropsy disclosed a blood clot in the facial canal. Since that time isolated cases have been reported, and in 1933 Griffith reviewed the published reports, and described 9 patients, of whom 3 were children. Clarke and Murphy (1956) reviewed 190 patients with malignant hypertension, and found 8 with isolated cranial nerve palsies; 7 of these had a facial paralysis.

In an attempt to assess the incidence of hypertension as a cause of facial palsy we have reviewed all cases of severe hypertension seen at this hospital in the past 10 years, and have also analysed the causes of facial palsy seen during the same period. The possible anatomical sites and pathological causes of this complication are presented below.

\section{Anatomy}

The facial paralysis in our patients involved the lower motor neurone only, indicating that the lesion must be located somewhere between the nucleus in the pons and the exit of the nerve from the stylomastoid foramen. The various sites where a lesion might occur are illustrated in the accompanying diagram (Fig.).

\section{Physiology}

The facial nerve, by its branches, serves particular functions with regard to salivation, lacrimation, taste, and hearing. By testing for these modalities, further evidence as to the site of the lesion may be obtained. Although the presence of lacrimation

Received August 11, 1965. can be easily observed in infants and children, methods of testing for salivation and taste are unreliable.

\section{Pathology}

The pathogenesis of the facial paralysis is uncertain, but vascular lesions are a well-known complication of malignant hypertension, and could occur at any site in the course of the nerve. Direct pressure from a thickened vessel, or oedema associated with raised intracranial tension could also be responsible for the paralysis.

In the only two necropsies that have been reported (Moxon, 1869; Monier-Vinard and Puech, 1930) the lesion has been a haemorrhage into the facial canal.

\section{Case Report}

D.H. Aged 18 months. $\mathrm{He}$ was referred in December 1964 on account of a urinary infection. 6 weeks later he presented with a left lower motor neurone facial palsy. On admission to hospital he was found to have a blood pressure of $240 / 130 \mathrm{~mm}$. $\mathrm{Hg}$, and papilloedema.

Extensive investigations, including pyelography, aortography, radioactive renograms, hormonal assays, and ultimately an open renal biopsy failed to reveal a cause for his hypertension.

Following treatment with methyldopa, satisfactory control of his blood pressure was obtained. Two months later the facial palsy had completely recovered.

It was concluded that the site of the lesion in his case was in the facial canal, below the origin of the nerve to the stapedius, as he retained lacrimation, and audiograms were normal. It was found impossible to test for taste and salivation.

A review of 35 cases of severe hypertension seen at this hospital in the past 10 years revealed a further 6 children who had had one or more episodes of facial paralysis during the course of their illness. The relevant details are summarized in Table I. An analysis of the causes of facial palsy seen during the same period is shown in Table II. 


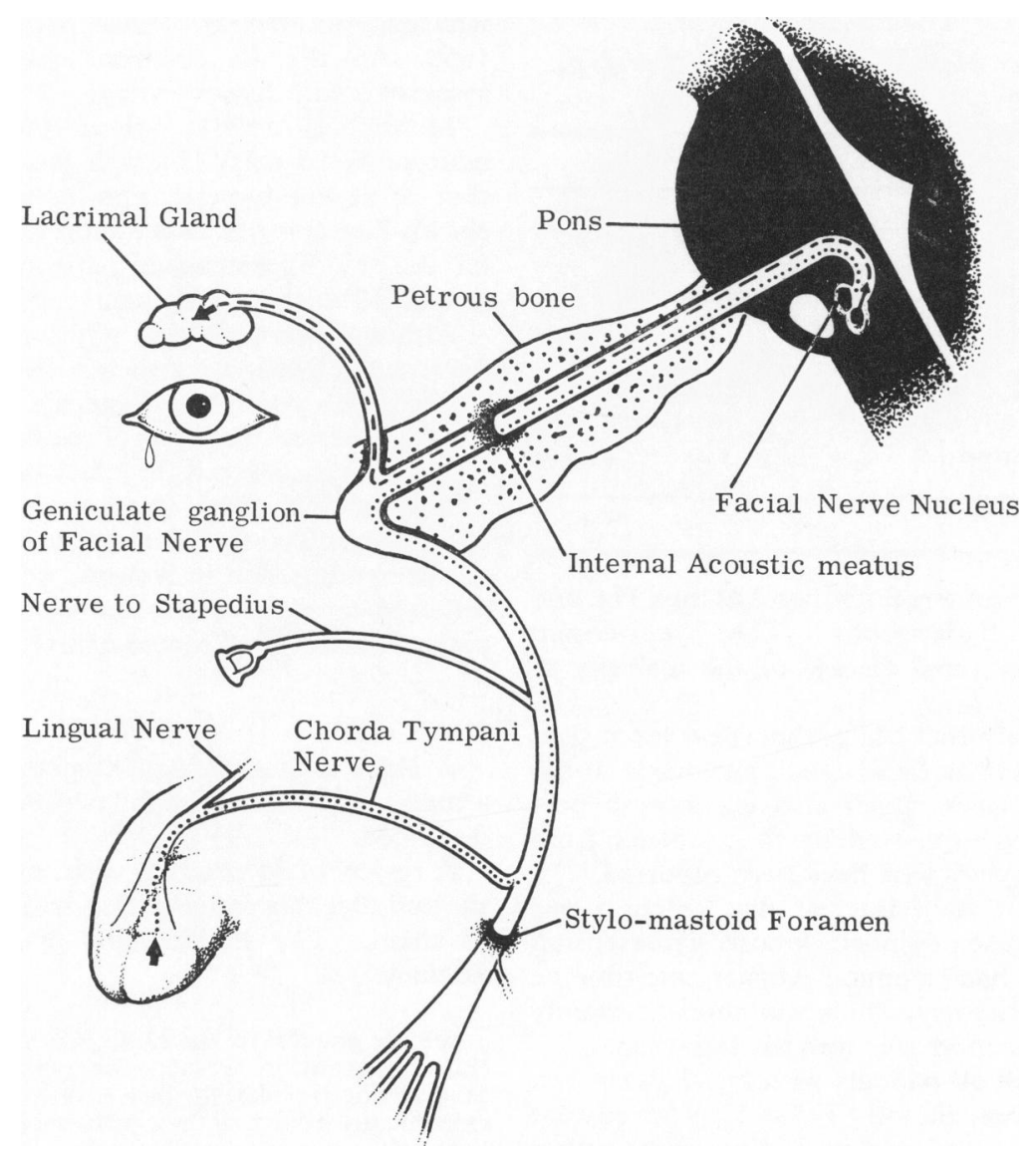

FIG.-Anatomy of the facial nerve.

\section{Discussion}

Certain features in the history of these children are interesting. Facial palsy was the presenting symptom in 3 patients. The onset of the paralysis usually coincided with a rise in the blood pressure, and improved when this was controlled; its duration varied from days to weeks. 2 patients had a second attack, corresponding with an exacerbation of their hypertension. The paralysis was always unilateral, and affected the right side in 4 cases, and the left in 3. The only common aetiological factor was the presence of severe hypertension, as shown

TABLE I

Patients with Hypertension and Lower Motor Neurone Facial Palsy (1954-1965)

\begin{tabular}{|c|c|c|c|c|c|}
\hline Patient & Age (yr.) & Diagnosis & $\underset{(\mathrm{mm} . \mathrm{Hg})}{\operatorname{Maximum}} \mathbf{B P}$ & Optic Fundi & Outcome \\
\hline $\begin{array}{c}\text { S.K. } \\
\text { D.H. } \\
\text { (Case report) } \\
\text { L.W. } \\
\text { J.J. } \\
\text { J.S. } \\
\text { T.H. } \\
\text { S.V. }\end{array}$ & $\begin{array}{l}1 \\
1 \frac{1}{2} \\
2 \frac{1}{2} \\
3 \\
3 \\
3 \\
13\end{array}$ & $\begin{array}{l}\text { Haemophilia } \\
\text { Renal haematoma } \\
\text { ? Pyelonephritis } \\
\text { Renal artery stenosis } \\
\text { Chronic pyelonephritis } \\
\text { Polycystic kidneys } \\
\text { Renal artery stenosis } \\
\text { Chronic pyelonephritis }\end{array}$ & $\begin{array}{l}200 / 120 \\
240 / 140 \\
270 / 160 \\
280 / 150 \\
190 / 110 \\
250 / 170 \\
260 / 180\end{array}$ & $\begin{array}{c}\text { Normal } \\
\text { Papilloedema } \\
\text { Normal } \\
\text { Papilloedema } \\
\text { Normal } \\
\text { Normal } \\
\text { Papilloedema }\end{array}$ & $\begin{array}{l}\text { Died } \\
\text { Alive } \\
\text { Died } \\
\text { Died } \\
\text { Died } \\
\text { Cured } \\
\text { Died }\end{array}$ \\
\hline
\end{tabular}


TABLE II

Causes of Lower Motor Neurone Facial Paralysis (1954-1964)

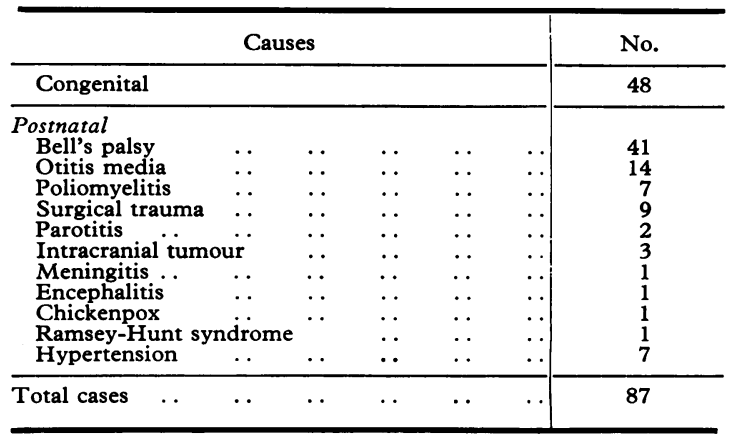

by a diastolic pressure greater than $120 \mathrm{~mm}$. Hg, and left ventricular hypertrophy. The hypertension was the result of renal disease in the majority of cases.

It appears likely that the pathological lesion is a haemorrhage into the facial canal, analogous to the retinal haemorrhages which also occur in hypertension. This is supported by the evidence from the only 2 necropsies that have been reported. In this connexion it is of interest that amongst our patients was a haemophiliac, whose hypertension followed a renal haematoma. At the same time he developed a facial palsy, which was almost certainly the result of a haemorrhage into the facial canal.

The analysis of all patients with facial palsy seen during this 10 -year period (Table II) showed that the great majority of acquired cases were either associated with otitis media, or were idiopathic (Bell's palsy). In both these groups recovery was usually complete and rapid. The prognosis in all the acquired cases was much better than in those due to developmental anomalies, which often required some form of surgical reconstruction. The paralyses that resulted from surgical trauma followed removal of large tumours of the head and neck, or radical mastoidectomy. Hypertension accounted for $8 \%$ of postnatal cases.

The only comparable series is that of Paine (1957), from Boston Children's Hospital Medical Center, who analysed 80 cases of facial palsy seen from 19431950. Of the 47 postnatal cases, only 2 were associated with hypertension.

McMichael (1961) states that lower motor neurone facial palsy is a well-recognized complication of severe hypertension in adults. We have shown that it is not uncommon in children, since 7 of the 35 hypertensive patients reviewed here developed this complication.

Although the prognosis with regard to the facial paralysis is good, nevertheless 5 of our 7 patients died within a year of the diagnosis. This emphasizes that hypertension is one of the most serious causes that can be discovered for a facial paralysis.

In view of the high incidence of hypertension in our series, added to the fact that the facial palsy was the presenting sign in 3 cases, we would stress the importance of recording the blood pressure in all patients with lower motor neurone facial paralysis.

\section{Summary}

A child with malignant hypertension, who presented with a lower motor neurone facial palsy, is described.

A review of 35 children with severe hypertension showed that this complication had occurred in $20 \%$ of them. The implications of this finding are discussed.

We are grateful to Dr. D. G. Cottom for his help and encouragement in writing this paper, to the Medical Staff at The Hospital for Sick Children for permission to examine the records of their patients, and to Mr. Geoffrey Lyth who prepared the illustration of the facial nerve.

\section{REFERENCES}

Clarke, E., and Murphy, E. A. (1956). Neurological manifestations of malignant hypertension. Brit. med. $\mathcal{F}$., $2,1319$.

Griffith, J. Q., Jr. (1933). Involvement of the facial nerve in malignant hypertension. Arch. Neurol. (Chic.), 29, 1195.

McMichael, J. (1961). Reorientations in hypertensive disorders. Brit. med. f., 2, 1239, 1310.

Monier-Vinard, and Puech, P. (1930). Néphrite chronique et paralysie faciale. Bull. Soc. méd. Hôp. Paris, 977.

Moxon, W. (1869). Apoplexy into canal of Fallopius in a case of Bright's disease, causing facial paralysis. Trans. path. Soc. Lond., 20, 420.

Paine, R. S. (1957). Facial paralysis in children. Review of the differential diagnosis and report of ten cases treated with cortisone. Pediatrics, 19, 303. 